\title{
Prevalencia del síndrome de Burnout en personal de salud del Hospital Distrital Inmaculada Concepción, Caaguazú
}

\author{
Andrés Paredes Rojas¹, Luz Paredes Rojas², Dulce Espínola Chaparro², \\ Isheli Espínola Figueredo², Ahabeli Espínola Figueredo², Vanessa \\ Paredes Rojas ${ }^{2}$
}

\section{Resumen}

Introducción: El rol del profesional del campo de la salud, implica la habilidad para poder enfrentar y afrontar situaciones en las que intervienen el sufrimiento, dolor e incluso la muerte. Ahora bien, en los últimos tiempos el Síndrome de Burnout se ha incrementado como un problema crucial que atañe a los profesionales de la salud; la misma se define como una respuesta inadecuada al estrés crónico en el trabajo, a largo plazo y acumulativo, con consecuencias a nivel individual y organizacional; y se caracteriza por su tridimensionalidad: agotamiento emocional, despersonalización, reducida realización personal. Este estudio permite crear las estadísticas en relación a esta problemática en profesionales de la salud en nuestro medio. A su vez, permitirá formular estrategias de promoción y prevención que puedan, para mejorar el estado de salud del personal y relación médico-paciente.

Objetivo: Determinar la prevalencia del Síndrome de Burnout en personal de salud del Hospital Distrital Inmaculada Concepción, año 2019.

Material y Método: Estudio observacional, descriptivo de prevalencia de corte transversal con muestreo no probabilísticos tomadas de manera casuística dentro del previo del Hospital Distrital Inmaculada Concepción de la ciudad de Caaguazú, previa autorización de las autoridades de dicha institución. Para la recolección de datos se utilizó el instrumento de MBI-HSS (Maslach y Jackson). El cálculo de la muestra se realizó mediante el programa Epiinfo V7, donde se consideró una población de 151 profesionales, frecuencia esperada del 50\%, un límite de confianza de 5\% con un nivel de confianza de 95\% arrojando como número mínimo 103 profesionales como muestra representativa.

Resultados: Se incluyó 103 personales de salud, donde se observó un nivel de

1. Universidad Nacional de Concepción, Facultad de Ciencias Médicas, Paraguay.

2. Universidad Santa Clara de Asís. Caaguazú, Facultad de Ciencias de la Salud, Paraguay.

E-mail: kukiparedes_17@hotmail.com

DOI: 10.26885/rcei.foro.2019.251

Trabajo publicado en acceso abierto bajo Licencia Creative Commons. 


\section{Paredes Rojas, A. et al. Prevalencia del Síndrome de Burnout en personal de salud}

Burnout de $23 \%$, el agotamiento emocional fue de $28 \%$, la despersonalización fue de $24 \%$, y la realización personal se encontró en un 51\%. Los participantes con mayores valores en el Burnout, tenemos que según el estado civil, son $11(10,7 \%)$ casados, en cuanto a la distribución por lugar de residencia, se puede apreciar que $15(14,6 \%)$ de los profesionales proceden de la ciudad de Caaguazú, la misma cifra se aplica a los participantes con hijos. La profesión con mayor prevalencia fue el personal de enfermería con una cantidad de $9(8,7 \%)$ participantes de las cuales $7(6,8 \%)$ se desempeñaban en el área guardia del sector de internados con turno diurno y un promedio de 41,9 horas semanales de trabajo.

Conclusiones: En el ámbito profesional paraguayo, el profesional sanitario se ve expuesto con frecuencia a la sintomatología propia del Síndrome de Burnout, afectando su nivel de identificación con el paciente y su rendimiento emocional principalmente. La mayoría las condiciones laborales y demográficas no se relacionan con la experiencia de desmoralización individual en el trabajo, conllevando a la necesidad de exploración de los recursos personales y psicológicos.

Palabras clave: agotamiento psicológico, salud mental, MBI-HSS.

\section{RefERencias}

Estigarribia, G., Acha Rodriguez, L. C., Guerrero, C. (2018) Prevalencia del Síndrome de Burnout en Médicos del Hospital Regional de Coronel Oviedo, 2017. Revista Facultad de Ciencias Médicas UNCA, 1(1). https:// ojs.fcmunca.edu.py/index.php/v1n1/article/view/15

Hernández Gracia, D. T. J., \& García Velázquez, D. M. del R. (2015). Agotamiento profesional y estrés: hallazgos desde méxico y otros países latinoamericanos. Boletín Científico De Las Ciencias Económico Administrativas Del ICEA, 4(7). https://doi.org/10.29057/icea. v4i7.176

Hernández Gracia, D. T. J., García Velázquez, D. M. R. (2015). Agotamiento profesional y estrés: hallazgos desde México y otros países latinoamericanos. ICEA, 4(7). https://repository.uaeh.edu.mx/revistas/ index.php/icea/article/view/176

Pines, A. M., Aronson, E., \& Kafry, D. (1981). Burnout: From Tedium to Personal Growth. New York: The Free Press.

Vargas-Terrez, B., Moheno-klee, V., Cortés-Sotres, J. F., Heinze-Martin, G. (2015). Médicos residentes: rasgos de personalidad, salud mental e ideación suicida. Investigación en Educación Médica, 4(16). http://www.scielo. org. $\mathrm{mx} /$ scielo.php? pid=S2007-50572015000400229\&script $=$ sci_ abstract\&tlng=en 